\begin{tabular}{|c|c|c|}
\hline PORT SAID ENGINEERING RESEARCH JOURNAL & Faculty of Engineering - Port Said University \\
& Volume (21) No. (2) September 2017 pp. 154:163 \\
\hline
\end{tabular}

\title{
Finite Element Analysis Verification of Experimental Work Results of a Single Point Incremental Sheet Metal Forming of Aluminum 6061
}

\author{
Noha Naeim* ${ }^{*}$, Ahmed Elkaseer ${ }^{2}$, Hassan Abd El-Hafez ${ }^{3}$, Ahmed Nassef $^{4}$
}

\begin{abstract}
In this paper, finite-element modeling (FEM) was developed to simulate the incremental sheet metal forming technique. The study mainly focused on the manufacture of complex shapes and modeled using ABAQUS/Explicit finite-element code as a simulation tool. Accordingly, a series of simulation trials have been carried out and the obtained results validated via experimental tests. The results indicated that the increasing of incremental depth increased the deformation force and this causing an increase of the stress. Also, the increase of the incremental depth from $0.5 \mathrm{~mm}$ to $1.0 \mathrm{~mm}$ increasing the sheet thinning from $0.8 \mathrm{~mm}$ to $0.698 \mathrm{~mm}$. Moreover, the increasing of feed rate increased the thinning with the same value for both of FEM and experimental tests. Furthermore, the results showed that the incremental depth has a significant effect on the surface roughness and sheet thickness and that feed rate have found to be the second effective parameter.
\end{abstract}

Keywords: Single Point Incremental Forming; Dieless Forming Process; Aluminum 6061; Finite Element Modeling.

\section{Introduction}

Sheet metal industry included different forming techniques which are mainly based on the usage of punches and dies with the accurate geometry of the deformed part [1].Incremental Sheet Metal Forming (ISMF) is a new technique for manufacturing sheet metal parts which is adequate for small batch production and prototyping [2, 3, 4].In the single point incremental forming of sheet metal, a simple hemispherical tool was used to make plastic deformation locally on the sheet in a

\footnotetext{
1 Department of Production Engineering and Mechanical Design, Faculty of Engineering, Port Said University, Port Fuad, 42523, Egypt, Email:nfouad39@gmail.com

2, 3, 4 Department of Production Engineering and Mechanical Design, Faculty of Engineering, Port Said University, Port Fuad, 42523, Egypt.
}

sequential paths using CNC milling machine $[5,6]$. The tool moves in both horizontally and vertically directions by a tool-path CAD program, and forms the final shape from the original sheet. This method is very flexible and has a large number of parameters that affect the forming results. $[2,7,8]$

The conventional methods of sheet metal forming are compatible only for mass production due to the high cost of equipment and die. As a result, many Researchers head for developing new forming methods for a batch size production with low cost. Single Point Incremental Forming (SPIF) technique with simple hemispherical tool is gained an excessive attention among different nonconventional forming processes $[9,10]$. 
In the last decades $\mathrm{FE}$ analysis was consuming large amount of time and efforts but after intensive work, a variety of commercial software, such as LS-DYNA®, ASNYS $®, \quad$ DYNAFORM $®, \quad$ DYNA-DIE®, and ABAQUS $®$ became available for modeling and simulating these processes. A study on metal forming are conducted using finite element method (FEM) as a simulation tool to investigate the deformation mechanics [11].

Finite element method (FEM) was developed in 1943 by R. Courant [12], who used the Ritz method of numerical analysis and minimization of vibration calculus to obtain approximate solutions for systems of vibration. It is used to design new products, as well as refinement of the existed products. Study of the physical parameters such as temperature and stress distributions precisely play a pivotal role for predictive process engineering of deformation processes [12].

There are systematic steps to convert the physical problem to finite element model; the first one is precisely idealized the problem where the model should be defined to problem behavior. The second step is generating the tool path of the simulated product. FEA is a practical simulation of process and it needs to be related to the flow curve and material properties because the conjunction between the deformed material and the target model.

This paper is organized as follows. Firstly, a review of related work is presented. Secondly, the systematic procedure to carry out the simulation study is given. Furthermore, the setup of the experimental tests and CNC machine is discussed. Thirdly, the achievable results of the simulation tests are described followed by a discussion of the agreement and discrepancy between these results and the experimental ones. Finally a summary with some conclusions based on the results and discussions is given.

\section{Related Work}

Cerro et al., [13] studied the effect of different incremental sheet forming (ISF) parameters on the characteristics of the parts produced by incremental sheet forming. A FEM of incremental sheet forming was executed using ABAQUS/Explicit software. Accordingly, the authors concluded that when the stage overlapping is higher, the thickness results are better and closer to the experimental values.

Nguyen et al., [14] improved the forming conditions for incremental sheet metal forming by changing the variables such as tool radius, tool step over, and friction coefficient according to Taguchi's method. The shape distribution of the surface profile showed a good agreement between the experimental and FE results. The formability of incremental sheet forming process was improved by using tool radius of $4 \mathrm{~mm}$, tool down step of $0.7 \mathrm{~mm}$, and coefficient of friction of 0.1 .

Tamer et al., [15] distinguish between the implicit and explicit finite element analysis of single point incremental forming. The results showed that the explicit methods used were fast and accurate in estimation of the element geometry in ISF. Furthermore, the implicit method provides more accurate results of geometry and strains.

Shanmuganatan and Kumar [16] studied the deformation of sheet metal parts by computerized numerical control (CNC) movement of a simple tool. They analyzed the effect of parameters such as tool diameter, depth of forming and thickness of sheet on wall angle, surface roughness $(\mathrm{Ra})$ and thinning. A finite element modeling was made to simulate the process using ABAQUS. The authors found that surface roughness decreases with the increase in the wall angle and tool diameter.

León et al., [17] examined the effect of geometrical parameters on the mechanical properties of incremental 
sheet forming parts. They found that the mean value of strain increases with the increase of the thickness. The sheet thickness found to have a significant effect on the applied maximum force.

Gómez-López et al., [18] discussed the sheet metal conformability and the friction phenomena on the incremental sheet metal forming especially at steel implementation. The results illustrate that the stress values are not large while the output strain should be greater from the forming viewpoint of Incremental Sheet Forming Processes.

Suresh et al., [19] suggested a methodology to input the tool path created using CAM packages into numerical simulation. The methodology was carried out using Matlab and Ls-Dyna. The results demonstrated that the suggested methodology was able to produce the required tool path trajectory with good geometric and dimensional accuracy.

Arfa et al., [20] investigated the applicability of the numerical technique and the experimental test of incremental forming of sheet metal. The influence of the sheet thickness, the tool path and the deformation behavior is examined with different tool paths. The author found that the forming force increases with the increase of sheet thickness. Plastic strain increases with tool increments.

Ben Ayed et al., [21] developed a simplified FE model called (ISF-SAM) to simulate the ISF process and it was completely efficient in terms of CPU time. The results showed that a reduction of the CPU time in the range of $63 \%$ has been acquired and at the same time good simulation results are carried out and compared with experimental results.

Naranjo et al., [6] studied the effect of technological parameters of single point incremental forming process using ANSYS software for simulating the process. They found that a small elements size must be applied for achieving a good convention with experimental results. A mesh size lower than $4 \mathrm{~mm}$ needs extended time for computation for square shapes while a mesh size for conical cups.

With a newly modeling technique the present study is to investigate the reduction of aluminum 6061 sheet thickness. Tests were performed for two different values of feed rate, i.e., 1125 and $2250 \mathrm{~mm} / \mathrm{min}$ and two different values of incremental depth, i.e., 0.5 and 1.0 $\mathrm{mm}$. The corresponding induced spindle speed and shear angle were fixed at $2000 \mathrm{rpm}$ and $30^{\circ}$. The above mentioned literature survey show however, a lack of stress analysis. A few published papers dealing with the effect of single point incremental sheet metal forming parameters on the sheet thickness and stresses. So, the objective of the current research is to investigate the prediction of stresses, strains and thickness distribution using numerical analysis as well as experimental study.

\section{Simulation and Experimental validation}

For simulation process a CAE Abaqus explicit software package was used .The program was designed to perform the reduction of thickness calculation and also the stresses on the sheet model during deformation process. Tables (1 and 2) illustrate the mechanical properties and the chemical composition of the sheet metal (Aluminum 6061) as received which used in the experimental and the simulation respectively.

Table 1: Al 6061 Mechanical properties

\begin{tabular}{|c|c|c|}
\hline Mechanical properties & Value & Units \\
\hline Young's Modulus $(\mathrm{E})$ & 69.3 & $G P a$ \\
\hline Yield Strength $\left(\sigma_{\mathrm{y}}\right)$ & 66.8 & $\mathrm{MPa}$ \\
\hline Poison ratio $(v)$ & 0.33 & ----- \\
\hline Density $(\rho)$ & 2800 & $\mathrm{Kg} / \mathrm{m}^{3}$ \\
\hline
\end{tabular}


Table 2: Al 6061 Chemical composition (wt. \%)

\begin{tabular}{|c|c|c|c|c|c|}
\hline $\mathrm{AL}$ & $\mathrm{Si}$ & $\mathrm{Mn}$ & $\mathrm{Cu}$ & $\mathrm{Mg}$ & $\mathrm{Fe}$ \\
\hline Balance & 0.5113 & 0.001 & 0.203 & 0.805 & 0.36 \\
\hline
\end{tabular}

Each part within the model was exposed to either type of fixation. Then, the boundary conditions are selected according to each particular actual process (Dynamic/ Explicit). Each part is divided to small elements using meshing module (C3D8R) through constant thickness of $0.8 \mathrm{~mm}$.

The results were computed using four node shell elements with reduced integration (S4R) which are available in the ABAQUS finite element analysis CAE. The computations were realized using explicit as well as implicit time schemes available in ABAQUS. Furthermore, modeling of the contact between the sheet metal and the tools is an essential part of the simulation. The interaction between the rigid tools and the deformable sheet metal is modeled using a penalty nodeto-surface contact method. Whenever a node of one body penetrates a segment of the other one, forces are applied to the slave nodes (sheet metal) to oppose the penetration, while equal and opposite forces act on the rigid tool surfaces at the penetration point. The sliding between the interacting surfaces is realized as finite-sliding formulation. This formulation allows for sliding, and rotation of the surfaces. As in the explicit analysis the time increments are small, and it is therefore assumed that the tangential motion between the two surfaces in contact does not significantly exceed the dimensions of the master surface facets. After completion of finite element calculations, visualization stage shows the final shape of the deformed sheet. The effect of Single Point Incremental Forming (SPIF) parameters on the stress distribution of the final shape is illustrated in Fig. 2.

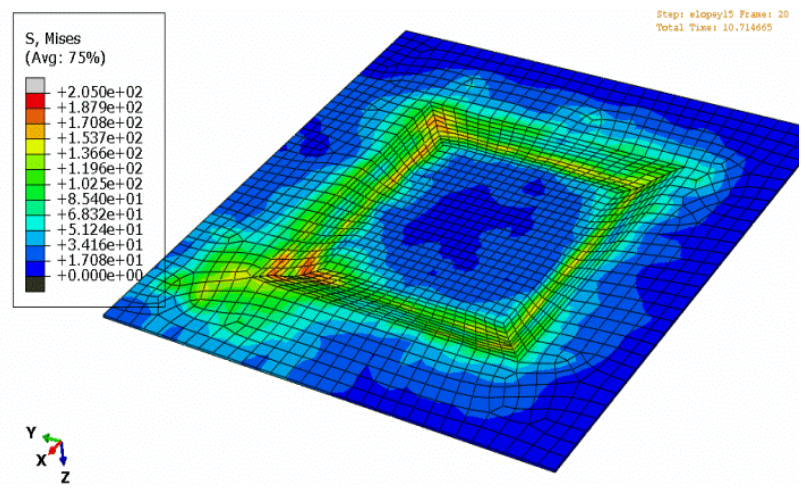

(a)

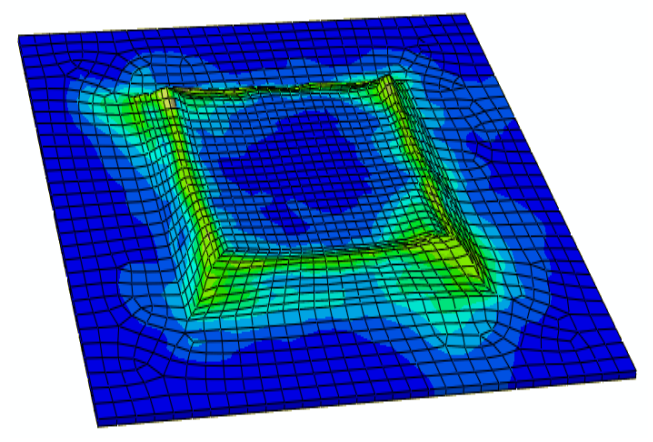

(b)

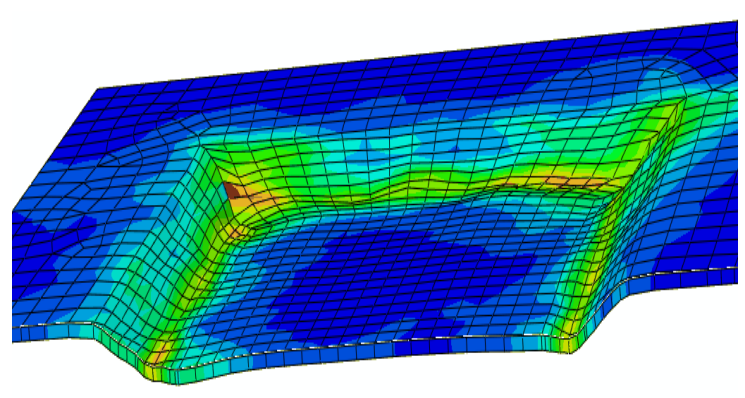

(c)

Fig. 2: Final deformed Shape, (a) front view,

(b) back view, and (c) cross section view

To validate the simulation study, experimental tests are carried out with the same conditions of the simulation study. The material used in the present study is aluminum sheet (6061) with thickness of $0.8 \mathrm{~mm}$. The test samples were prepared and cut in dimension of $200 \times 200 \mathrm{~mm}$. A 
fixture was employed to clamp the sheet metal during the process and a hemispherical forming tool was utilized. A simple pyramid shape has been selected to carry out the experimental work. An Extron CNC milling machine was used to generate the pyramid shape of the final part as shown in Fig. 3.

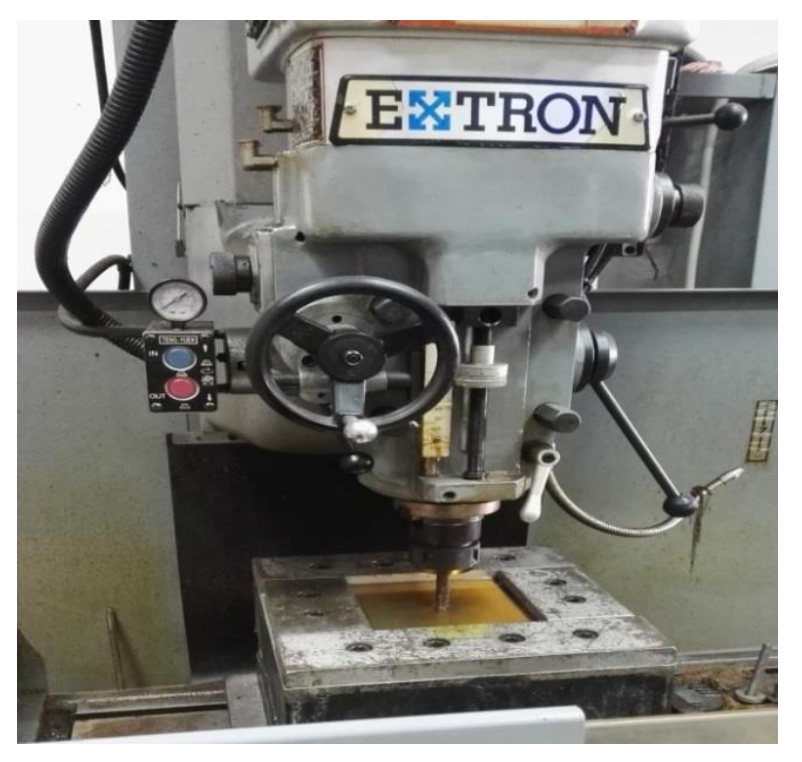

Fig. 3: An Extron CNC milling machine and setup

\section{Results and Discussion}

Fig. 4 shows the different prediction stress distributions of deformed parts for two different values. The variation of the feed rate and incremental depth were in the range of 1125 and $2250 \mathrm{~mm} / \mathrm{min}$ and 0.5 and $1.0 \mathrm{~mm}$ respectively. The corresponding induced spindle speed and shear angle were fixed at $2000 \mathrm{rpm}$ and $30^{\circ}$.
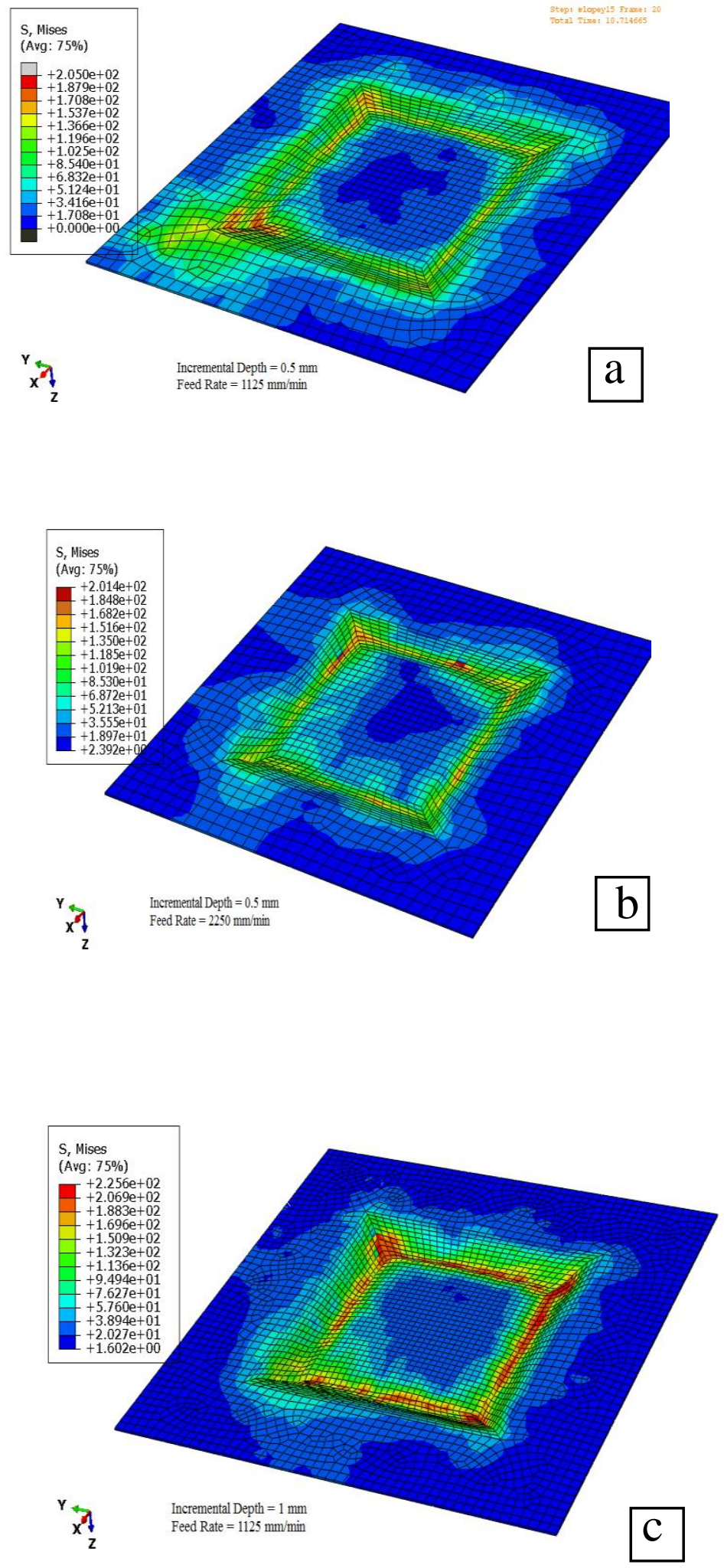


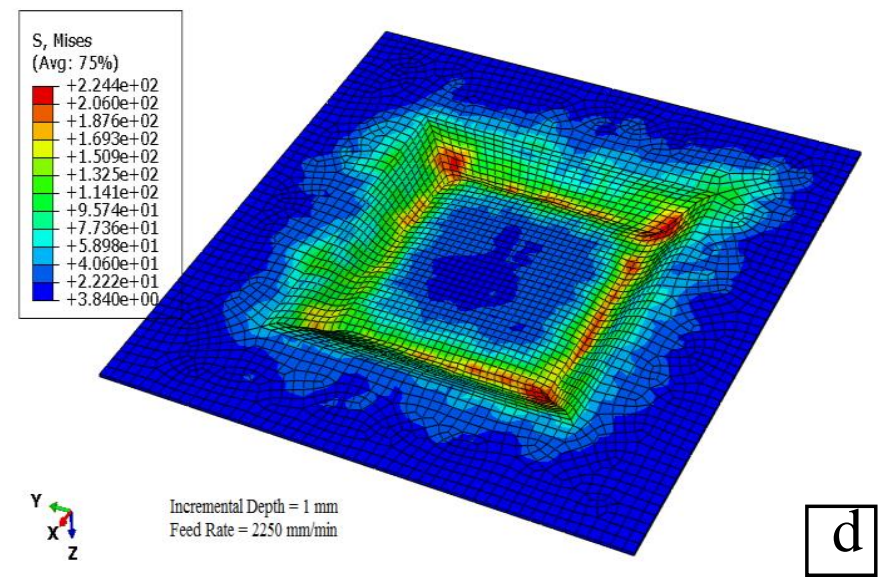

Fig. 4: The different prediction stress of deformed parts, (a) $\Delta z=0.5 \mathrm{~mm}, F r=1125 \mathrm{~mm} / \mathrm{min}$, (b) $\Delta \mathrm{z}=0.5 \mathrm{~mm}, \quad F r=2250 \mathrm{~mm} / \mathrm{min}$, (c) $\Delta z=1.0 \mathrm{~mm}, \quad F r=1125 \mathrm{~mm} / \mathrm{min}$, and (d) $\Delta z=1.0 \mathrm{~mm}, \mathrm{Fr}=2250 \mathrm{~mm} / \mathrm{min}$

It can be noticed that from Fig. 4a, that the incremental depth is $0.5 \mathrm{~mm}$ and the feed rate is $1125 \mathrm{~mm} / \mathrm{min}$. The maximum stress generated in this case is $205 \mathrm{MPa}$. While, in Fig. $4 \mathrm{~b}$ the incremental depth is $0.5 \mathrm{~mm}$ and the feed rate is $2250 \mathrm{~mm} / \mathrm{min}$ and the maximum stress is201.4 MPa. From Fig. 4(a and b) it demonstrated that the stress increasing with the decreasing of feed rate and the minimum value of stresses obtained at lower incremental depth and higher feed rate. Also, in Fig. 4c the incremental depth is $1.0 \mathrm{~mm}$ and the feed rate is 1125 $\mathrm{mm} / \mathrm{min}$. The maximum stress generated in this case is 225.6 MPa. While, in Fig. 4d the incremental depth is 1.0 $\mathrm{mm}$ and the feed rate is $2250 \mathrm{~mm} / \mathrm{min}$ and the maximum stress is 224.4 MPa. From Fig. 4(c and d) it can be seen that the stress increases with the decreasing of feed rate and the maximum value of stresses obtained at higher incremental depth and lower feed rate. Due to the increasing of incremental depth the deformation force is increasing and this causing the increasing of the stress.

It also noticed that the increasing of the incremental depth form $0.5 \mathrm{~mm}$ to $1.0 \mathrm{~mm}$ increasing the stress from $205 \mathrm{MPa}$ to $225.6 \mathrm{MPa}$ and from $201.4 \mathrm{MPa}$ to $224.4 \mathrm{MPa}$ at constant feed rate of $1125 \mathrm{~mm} / \mathrm{min}$ and $2250 \mathrm{~mm} / \mathrm{min}$ with average value of $10 \%$ and $11.4 \%$ respectively. While, the increasing of the feed rate form $1125 \mathrm{~mm} / \mathrm{min}$ and $2250 \mathrm{~mm} / \mathrm{min}$ decreasing the stress from $205 \mathrm{MPa}$ to $201.4 \mathrm{MPa}$ and from $225.6 \mathrm{MPa}$ to $224.4 \mathrm{MPa} \%$ at constant incremental depth of $0.5 \mathrm{~mm}$ and $1.0 \mathrm{~mm}$ respectively.

The maximum normal stress (S33) occurred in condition (a) in $\mathrm{Z}$ - direction is $173.1 \mathrm{MPa}$, while the shear stress (S13) in XY direction is $82.73 \mathrm{MPa}$ as shown in Fig. 5

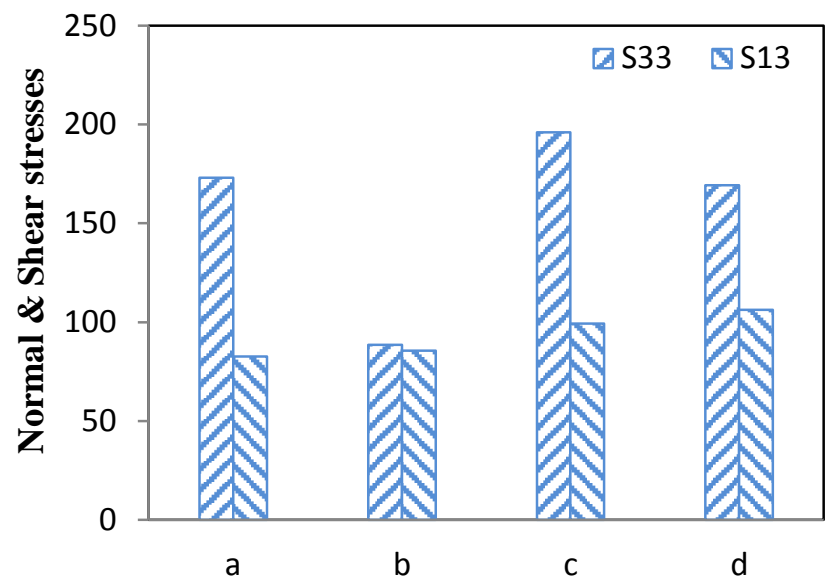

Fig. 5: Normal and shear stresses, (a) $\Delta z=0.5 \mathrm{~mm}, \quad F r=1125 \mathrm{~mm} / \mathrm{min}$, (b) $\Delta z=0.5 \mathrm{~mm}, \quad F r=2250 \mathrm{~mm} / \mathrm{min}$, (c) $\Delta \mathrm{z}=1.0 \mathrm{~mm}, \quad \mathrm{Fr}=1125 \mathrm{~mm} / \mathrm{min}$, and (d) $\Delta z=1.0 \mathrm{~mm}, \mathrm{Fr}=2250 \mathrm{~mm} / \mathrm{min}$

It can be seen that from Fig. 5a the shear stress in Zdirection $(\mathrm{S} 13)=0.5$ the normal stress in $\mathrm{XZ}$ direction (S33). As well as, the maximum normal stress (S33) occurred in conditions (b, c, and d) is 88.62, 196, and 169.3 MPa respectively; while the shear stress (S13) occurred in condition (b, c, and d) is $85.68,99.35$, and 106.2 MPa respectively.

A comparison of thickness distributions obtained from finite element model and other obtained experimentally with the same parameters was carried out. The thickness distribution of the four different models is illustrated in 
Fig. 5,and as expected there is a slight difference between the measured value and model results, so the model meshing has been refined in order to minimize the difference between measured and predicted values.
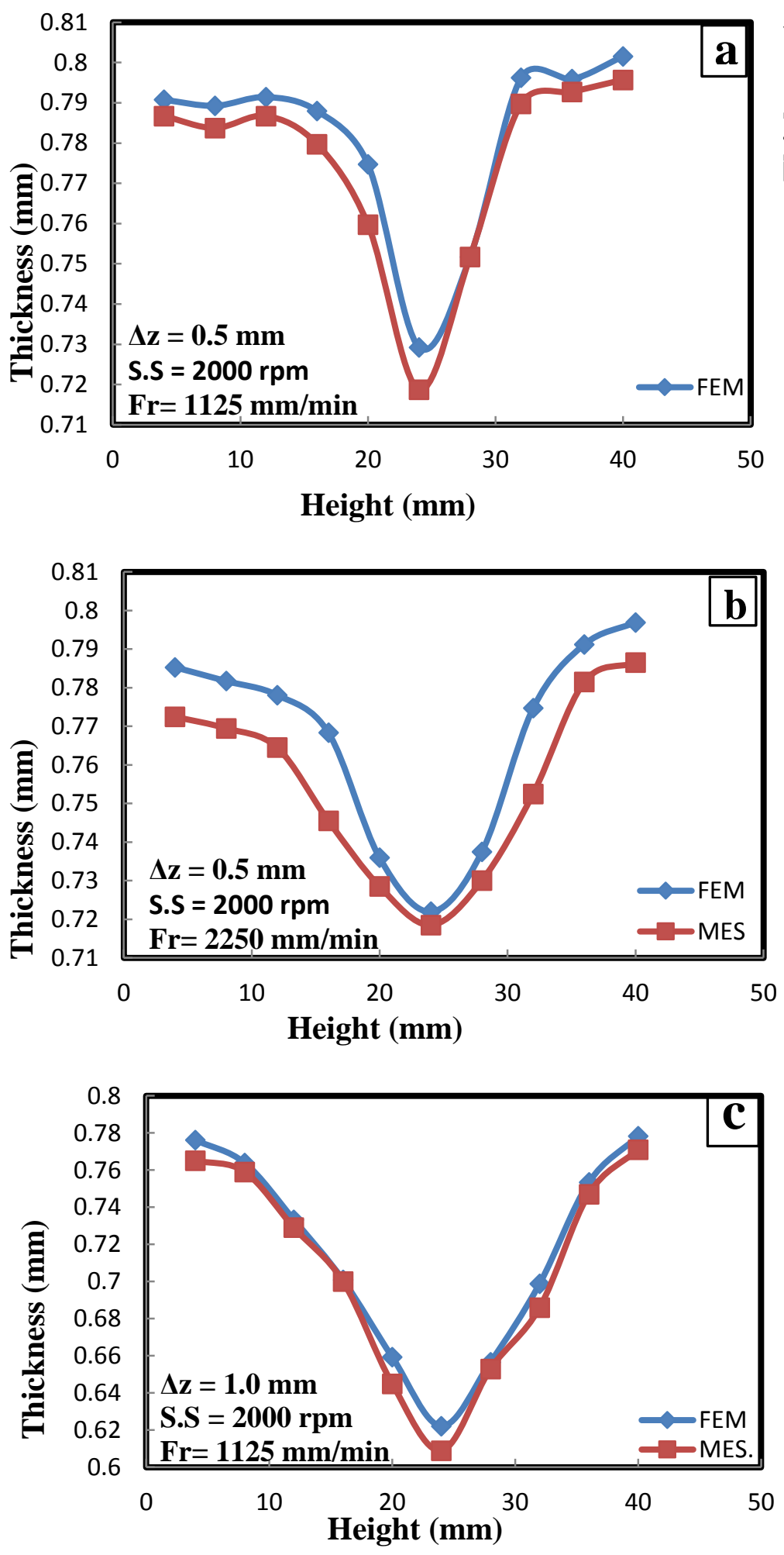

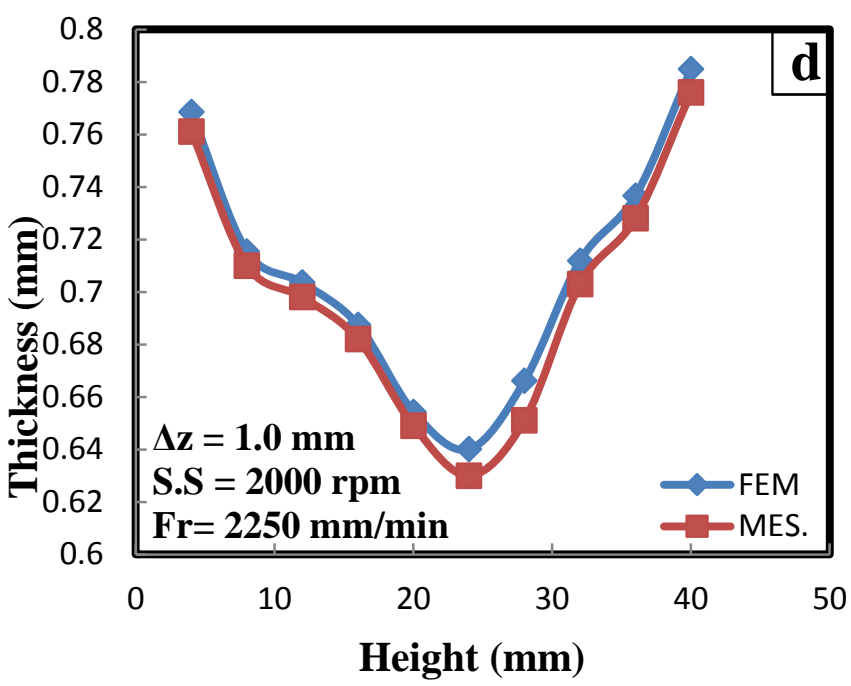

Fig. 6: Thickness distribution of FEM and experimental values, (a) $\Delta \mathrm{z}=0.5 \mathrm{~mm}, \mathrm{Fr}=1125$ $\mathrm{mm} / \mathrm{min}$, (b) $\Delta z=0.5 \mathrm{~mm}$, Fr $=2250 \mathrm{~mm} / \mathrm{min}$, (c) $\Delta z=1.0 \mathrm{~mm}, \quad F r=1125 \mathrm{~mm} / \mathrm{min}$, and (d) $\Delta z=1.0 \mathrm{~mm}, \mathrm{Fr}=2250 \mathrm{~mm} / \mathrm{min}$

It can be seen that in Fig. 6a the thickness decreasing slightly with the increasing of the part height till $\mathrm{h}=$ $12 \mathrm{~mm}$. The thickness decreasing sharply from height 12 $\mathrm{mm}$ to $24 \mathrm{~mm}$ due to the maximum stretching on the sheet thickness. Then the thickness increasing sharply till $\mathrm{h}=32 \mathrm{~mm}$ because of the undeforming part in the middle of the pyramid. It is clearly shown that the minimum value of the thickness is 0.729 and $0.719 \mathrm{~mm}$ for FEM and experimental tests respectively.

Fig. $6 \mathrm{~b}$ presents the relationship between the thickness distribution with the height of $\Delta z=0.5 \mathrm{~mm}, \mathrm{~S} . \mathrm{S}=2000$ $\mathrm{rpm}, \mathrm{Fr}=2250 \mathrm{~mm} / \mathrm{min}$. It is clearly showed that the entire figure nearly have the same tendency of Fig. 6a. It is shown that from the figures, the sheet thickness decreasing with average value of $9.8 \%$ for all the heights with constant incremental depth and increasing the feed rate value.

It can also observed that in Fig. 6c the thickness decreasing sharply with the height till $\mathrm{h}=24 \mathrm{~mm}$, and then it increased sharply with the further increase of the height. The minimum value of thickness is 0.622 and 
$0.609 \mathrm{~mm}$ for FEM and experimental tests respectively at height of $24 \mathrm{~mm}$.

The thickness decreasing sharply with the increasing of the height till $\mathrm{h}=8 \mathrm{~mm}$ to $\mathrm{h}=24 \mathrm{~mm}$ as shown in Fig. $6 \mathrm{~d}$. The thickness increasing sharply from $\mathrm{h}=28 \mathrm{~mm}$ to $\mathrm{h}$ $=40 \mathrm{~mm}$. It is clearly shown that the minimum value of the thickness is 0.640 and $0.63 \mathrm{~mm}$ for FEM and experimental tests respectively.

From Figs. 6(a, b, c, and d) it can be obtained that the increasing of the incremental depth increasing the sheet thinning with average value of 12.5 and $12.7 \%$ for FEM and experimental tests respectively. Moreover, the increasing of feed rate increasing the thinning with average value of $1 \%$ for both of FEM and experimental tests.

The actual sheet thickness was measured experimentally and compared with the obtained one from the simulation and the results are listed in Table. 2. It is clear from the results that there is a good agreement between the actual and simulation shear angle value and this considered as a good indicator for the capabilities of the FEM.

Table.2: Comparison between the experimental measured thickness and finite element analysis simulation thickness at various feed rate and different incremental depth at $\mathrm{h}=20 \mathrm{~mm}$.

\begin{tabular}{|c|c|c|c|c|}
\hline $\begin{array}{c}\text { Feed } \\
\text { rate } \\
\mathrm{mm} / \mathrm{min})\end{array}$ & $\begin{array}{c}\text { Incremental } \\
\text { depth } \\
(\mathrm{mm})\end{array}$ & $\begin{array}{c}\text { Measured } \\
\text { thickness } \\
(\mathrm{mm})\end{array}$ & $\begin{array}{c}\text { Simulation } \\
\text { thickness } \\
(\mathrm{mm})\end{array}$ & $\begin{array}{c}\text { Error } \\
\text { percentage } \\
\%\end{array}$ \\
\hline 1125 & 0.5 & 0.759 & 0.775 & -1.9 \\
\hline 1125 & 1.0 & 0.645 & 0.659 & -2.2 \\
\hline 2250 & 0.5 & 0.728 & 0.736 & -1.03 \\
\hline 2250 & 1.0 & 0.649 & 0.65 & -0.81 \\
\hline
\end{tabular}

\section{Conclusion}

As it has been observed, incremental sheet forming process is a promising manufacturing process which still requires further studies. The effect of process parameters, spindle speed, feed rate and incremental depth on the characteristics of aluminum 6061 sheet (thickness, stresses...) has been studied. Simple FEM process model is being developed in order to predict the behavior of the sheet during this forming process. The following conclusions were drawn based on the obtained results by incremental sheet metal forming experiments on Al.6061 and compared with the FEM.

1. The incremental depth has a significant effect on the obtained sheet thickness and that feed rate found to be the second effective parameter.

2. The finite element model solution time increased when decreasing vertical increment value.

3. The maximum obtained stress generated for $\mathrm{Al}$ 6061 is $225.6 \mathrm{MPa}$ at incremental depth of 1.0 $\mathrm{mm}$ and feed rate of $1125 \mathrm{~mm} / \mathrm{min}$.

4. The minimum stress obtained is $201.4 \mathrm{MPa}$ at incremental depth of $0.5 \mathrm{~mm}$ and feed rate of $2250 \mathrm{~mm} / \mathrm{min}$.

5. The increasing of incremental depth increasing the deformation force and this causing the increasing of the stress.

6. The increasing of the incremental depth increasing the sheet thinning with average value of 12.5 and $12.7 \%$ for FEM and experimental tests respectively. Moreover, the increasing of feed rate increasing the thinning with average value of $1 \%$ for both of FEM and experimental tests. 


\section{References}

[1] Shendage R.M. and Pujari S.M., 2014, "Effect of Process Parameters on Fracture Depth and Thickness Distribution in Single Point Incremental Forming", International Journal of Engineering Research \& Technology (IJERT), PP. 501-504.

[2] Jinish V.V and Manesh K. K, 2013, "Numerical Study on Single Point Incremental Sheet Metal Forming Process", International Journal of Emerging Technology and Advanced Engineering, ISSN 2250-2459, Volume 3, Issue 8, PP. 759-763.

[3] Dejardina S., Thibaudb S., Gelina J.C., Michela G., 2010," Experimental Investigations and Numerical Analysis for Improving knowledge of Incremental Sheet Forming Process for Sheet Metal Parts". Journal of Materials Processing Technology 210, PP. 363-369

[4] Echrif Salah B. M., Hrairi Meftah, 2011, "Process simulation and quality Evaluation of incremental sheet metal forming", IIUM Engineering Journal, Special Issue, Mechanical Engineering.

[5] Suresh Kurra, Khan Arman, Regalla Srinivasa Prakash, 2013, "Tool path definition for numerical simulation of single point incremental forming", International Conference on design and manufacturing, PP. $536-545$.

[6] Naranjoa J. , Miguela V., Martínez-Martínezb A. , Gómez-Lópeza L.M., Manjabacasa M.C., Coelloa J., 2015, "Analysis and simulation of Single Point Incremental Forming by ANSYS $®$ ", The Manufacturing Engineering Society International Conference, PP. 1104 $-1111$.

[7] Park Jong-Jin, Kim Yung-Ho,2003, "Fundamental studies on the incremental sheet metal forming technique", Journal of Materials Processing Technology 140, PP. 447-453.

[8] Emmensa W.C., Sebastianib G., van den Boogaardc A.H., 2010, "The technology of Incremental Sheet Forming-A brief review of the history", Journal of Materials Processing Technology 210, PP. 981-997.

[9] Malviya Vibhor, and Murali G., 2015, "Finite Element Analysis of Incremental Sheet Metal Forming", International Journal for Scientific Research \& Development, PP. 1432-1435.
[10] Julian M. and Allwood D. R. S., 2009, "Generalised Forming Limit Diagrams Showing Increased Forming Limits with Non-Planar Stress States." International Journal of Plasticity.

[11] ChelluruSaiKiran, 2004 "Finite Element Simulations of Ballistic Impact on Metal and Composite Plates", Masters of Science thesis, B.E., Andhra University.

[12] Tisza Miklós, Lukács Zsolt, Gál3 Gaszton, 2012, "Numerical Modelling of Hot Forming and HeatTreatment of Annular Gears", Journal of Production Processes and Systems, pp. 115-126.

[13] Cerro I. , Maidagan E. , Arana J. , Rivero A. , Rodr'1guez P.P., 2006, "Theoretical and Experimental Analysis of The Dieless Incremental Sheet Forming Process", Journal of Materials Processing Technology 177 , PP. 404-408.

[14] Nguyen D-T , Park J-G , Lee H-J , and Kim Y-S, 2009, "Finite Element Method Study of Incremental Sheet Forming for Complex Shape and Its Improvement", journal of Engineering Manufacture, PP. 913-924.

[15] Tamer M. E. , Music O., Ozdemir I., Baranoglu B., Sakin A. , Durgun I., 2013, "Simulation for Incremental Sheet Forming Process: a Comparison of Implicit and Explicit Finite Element Analysis with Experimental Data", 7th International Conference and Exhibition on Design and Production of Machines and Dies/Molds, PP. 29-36.

[16] Shanmuganatan S.P., Senthil Kumar V.S., 2013, "Metallurgical Analysis and Finite Element Modelling for Thinning Characteristics of Profile Forming on Circular Cup", journal of Materials and Design 44, PP. 208-215.

[17] Leóna J., Salcedoa D. , Ciáurriza C. , Luisa C.J. , Fuertesa J.P. , Puertasa I. , Luria R., 2013, “Analysis of The Influence of Geometrical Parameters on The Mechanical Properties of Incremental Sheet Forming Parts", The Manufacturing Engineering Society International Conference, PP. 445 - 453.

[18] Gómez-Lópeza L.M., Miguela V., Martínezb A. , Coelloa J. , Calatayuda A., 2013, "Simulation and Modeling of Single Point Incremental Forming Processes within a Solid works Environment", The Manufacturing Engineering Society International Conference, PP. 632 641. 
[19] Suresh Kurra , Khan Arman, Regalla Srinivasa Prakash, 2013, "Tool Path Definition for Numerical Simulation of Single Point Incremental Forming", International Conference on Design and Manufacturing, PP. $536-545$.

[20] Arfa H., Bahloul R., BelHadjSalah H., 2013, "Finite Element Modelling and Experimental Investigation of Single Point Incremental Forming Process of Aluminum Sheets: Influence of Process Parameters on Punch Force Monitoring and on Mechanical and Geometrical Quality of Parts", International Journal of Mater Form, PP. 6:483-510.

[21] Ben Ayed Lanouar, Robert Camille, Delam'ezi ere Arnaud, Nouari Mohammed, Batoz Jean-Louis, 2014, "Simplified Numerical Approach for Incremental Sheet Metal Forming Process", Elsevier, pp.75-86. 